\title{
Effect of Cooling Rate on The Plasma Nitriding Process of 304 Austenitic Stainless Steel
}

\author{
F. M. El-Hossary ${ }^{1}$, N. Z. Negm ${ }^{1}$, A. M. Abd El-Rahman ${ }^{1,2}$, A. A. Abd El-Moula ${ }^{1}$, \\ S.M. Khalil ${ }^{1,3,4^{*}}$ \\ ${ }^{1}$ Physics Department, Faculty of Science, Sohag University, 82524-Sohag, Egypt \\ ${ }^{2}$ Abdul-Aziz University, Jeddah, KSA \\ ${ }^{3}$ Umm Al-Qura University, University College, Alqunfadah, KSA \\ ${ }^{4}$ Umm Al-Qura University, Qunfadah Center for Scientific Research (QCSR), KSA
}

\begin{abstract}
The aim of this work is to study the influence of the cooling rate on the properties of the modified surface layer of AISI 304 steel after rf plasma nitriding. The nitrided samples were characterized by glow discharge optical spectroscopy, x-ray diffraction, optical microscopy, scanning electron microscopy and Vickers microhardness measurements. The results revealed that microstructure, nitriding rate and surface microhardness values were found to be cooling rate dependent. The treated layer is mainly composed of nitrogen expanded austenite $\left(\gamma_{\mathrm{N}}\right)$, iron nitride $\left(\gamma^{\prime}-\mathrm{Fe}_{4} \mathrm{~N}\right)$ and chromium nitride $(\mathrm{CrN})$. A maximum thickness of treated layer $(19.9 \mu \mathrm{m})$ is achieved for sample treated at medium cooling rate of $900 \mathrm{Cm}^{3} / \mathrm{min}$. It has a maximum surface hardness and nitriding rate of $1402 \mathrm{HV} 0.1$ and $0.66 \mu \mathrm{m}^{2} / \mathrm{s}$, respectively.
\end{abstract}

Keywords: AISI 304 stainless steel, rf plasma nitriding, cooling rate, surface morphology, nitriding rate, surface microhardness.

\section{INTRODUCTION}

Plasma surface modifications have been used in various industrial applications over the past several decades $[1,2]$. One of these applications is the development of machinery tools and components. To increase productivity and efficiency, high speed and high load operating machines were used in industrial production. Components of such machines are exposed to harsher and harsher conditions. Therefore, they have to be tougher and more resistant to wear at high operating temperatures without cooling emulsion. Dry cutting and drilling are good examples. Surface modification of such machinery tools and components addresses those needs due to improving their mechanical and tribological properties which lead to increasing their service lifetime.

Many tools and components are manufactured from different kinds of austenitic stainless steels due to their excellent corrosion resistance. However, the wider applications of austenitic stainless steels are restricted by their relatively poor mechanical and tribological properties. Plasma nitriding can be used as an effective surface modification technique to introduce nitrogen species into the surface of austenitic stainless steels to form various hard surfaces and sub surfaces composed of nitrides, keeping the bulk material without any modification $[3,6]$. This technique has been intensively studied over several decades and its basic principles are well known [7-10].

During plasma nitriding process, the surface of the treated substrate is exposed to chemical and physical reactions. The properties of the nitrided layer are affected by these reactions depending on the optimization of many process parameters. Intensive research work have been done on the effect of treatment temperature, processing time, processing power and, adding different ratios of hydrogen or carbon gas to nitrogen even surface roughness on the properties of the modified surface layer of different kinds of stainless steel substrates 


\section{Effect of Cooling Rate on The Plasma Nitriding Process of 304 Austenitic Stainless Steel}

[11-16]. Therefore, the present study focuses on the effect of cooling rate on the microstructure and mechanical properties of the treated layers.

\section{EXPERIMENTAL DETAILS}

AISI 304 austenitic stainless steel substrates were cut into coupons with dimensions $20 \mathrm{~mm}$ x $15 \mathrm{~mm}$ x $3 \mathrm{~mm}$. The chemical composition of austenitic substrate is $0.5 \mathrm{wt} . \% \mathrm{Si}, 1.2 \mathrm{wt} . \% \mathrm{Mn}, 8.5 \mathrm{wt} . \% \mathrm{Ni}, 19.1 \mathrm{wt} . \% \mathrm{Cr}, 0.075$ wt.\% C and $69.95 \mathrm{wt} . \%$ Fe. The nitriding process was carried out using inductively coupled rf plasma with a continuous mode of operation. The discharge was generated by a three-turn copper induction coil energized from a $13.56 \mathrm{MHz}$ rf power supply through a tunable matching network. The sample is mainly heated using the only source of $\mathrm{rf}$ plasma field. The treatment temperature is measured during the rf plasma process by a Chromel-Alumel thermocouple, which was lightly pressed on the surface of a blank sample. The untreated samples were only cleaned in acetone before entering the reactor tube of the rf plasma system. To meet the optimum condition of nitriding, the distance between the surface of the samples and rf coil was fixed at $21 \mathrm{~mm}$. Nitrogen gas was introduced into the reactor tube to increase the base pressure from $7 \times 10^{-3}$ to about $8 \times 10^{-2}$ mbar. All samples were treated at a fixed input plasma processing power of $450 \mathrm{~W}$ for 10 min while the water flow rate is varied from 100 to $2000 \mathrm{~cm}^{3} / \mathrm{min}$. At the end of the process, the nitrided sample was allowed in the evacuated atmosphere of nitrogen in the reactor tube until it cooled down to the room temperature.

In order to obtain a highly reflective surface of the nitrided layers for cross-section morphology investigation, the specimens should be carefully cut, grinded and exposed to subsequent polishing operations before they can be examined under optical microscope. Through this work, low speed saw of ISOMET ${ }^{\mathrm{TM}}$ is used for precise and deformation-free cutting of the treated specimens into small work pieces. Grinding was accomplished by abrading the specimen surface through a sequence of operations using progressively finer abrasive grit (silicon carbide) sizes from 40 mesh through 150 mesh were used as coarse abrasives, and grit sizes from 180 mesh through 400 mesh as fine abrasives. Polishing process was started by the abrasive grit of 600 and 1200 mesh. After that, the micro polish of Alumina suspensions ( 0.3 and 0.1 micron) ware used on the top of the laps to achieve high quality polished surface mirror like. Finally, the specimens were washed and swabbed in warm running water. To show the morphology of the cross section of the treated samples, $2 \%$ Nital etcher was used for exposure time of $30 \mathrm{sec}$. Then, the layer thickness was measured by a micrometer scale attached with the optical microscope and visibly confirmed by the optical images.

The microstructure of the nitrided layers was characterized by Philips x-ray Diffractometer using MoK $\alpha$ radiation $\left(\lambda=0.70930 \mathrm{~A}^{\circ}\right)$. A glow discharge optical spectroscopy (GDOS) was utilized to measure the elemental concentration depth profiles. Scanning electron microscopy (SEM) was employed to study the microstructure of treated samples. Vickers microhardness measurements were taken, at room temperature, using $100 \mathrm{~g}$ load.

\section{RESULTS AND DiscusSions}

\section{Surface temperature and temperature gradient}

Table (1) shows surface temperature and cooling rates values of austenitic stainless steel samples. It has been found that, the surface temperature was found to decrease continuously from 590 to $490^{\circ} \mathrm{C}$ with increasing the cooling rate from 100 to $2000 \mathrm{Cm}^{3} / \mathrm{min}$.

\section{Glow discharge optical spectroscopy (GDOS) analysis}

Fig.1 (a-c) shows the elemental concentration depth profiles of the constitutive elements iron (Fe), chromium $(\mathrm{Cr})$, nickel (Ni), oxygen (O), carbon (C), and nitrogen (N) for samples treated at different cooling rates of 100, 900 and $2000 \mathrm{Cm}^{3} / \mathrm{min}$. The concentration of nitrogen has approximately the same value of $25 \pm 1$ at. $\%$ in the near surface region for all nitrided substrates. The low variation of nitrogen concentration, at different cooling 


\section{Effect of Cooling Rate on The Plasma Nitriding Process of 304 Austenitic Stainless Steel}

rates, is ascribed to that the austenitic substrates were treated at fixed plasma processing power using the same flow rate of nitrogen. The substrates were achieving approximately the same plasma density of reactive nitrogen species which mainly controls nitrogen concentration gradient. In addition, the thermal contact between the bottom of the substrate and the top surface of the sample holder can be considered as a significant experimental factor, affecting treatment temperature and temperature gradient at fixed other processing parameters. This factor can be neglected in the present study by using austenitic substrates in a sheet form with the same dimensions positioned at the same location on the surface of the sample holder, besides cleaning the sample holder surface after each experiment to avoid any undesired coating might affect the thermal contact. However, it has observed that the amount of nitrogen diffused into the bulk substrate is a little bit low (20\%) for the sample treated at low cooling rate of $100 \mathrm{Cm}^{3} / \mathrm{min}$ with respect to that ones were treated at relatively medium and high cooling rate of 900 and $2000 \mathrm{Cm}^{3} / \mathrm{min}$, respectively.

Table1. Cooling rate and surface temperature of $3 \mathrm{~mm}$ thick austenitic stainless steels.

\begin{tabular}{|c|c|}
\hline Surface temperature $\left({ }^{\circ} \mathbf{C}\right)$ & Cooling rate $\left(\mathbf{c m}^{3} / \mathbf{m i n}\right)$ \\
\hline 590 & 100 \\
\hline 583 & 300 \\
\hline 580 & 500 \\
\hline 579 & 700 \\
\hline 567 & 900 \\
\hline 560 & 1100 \\
\hline 544 & 1400 \\
\hline 508 & 1700 \\
\hline 490 & 2000 \\
\hline
\end{tabular}

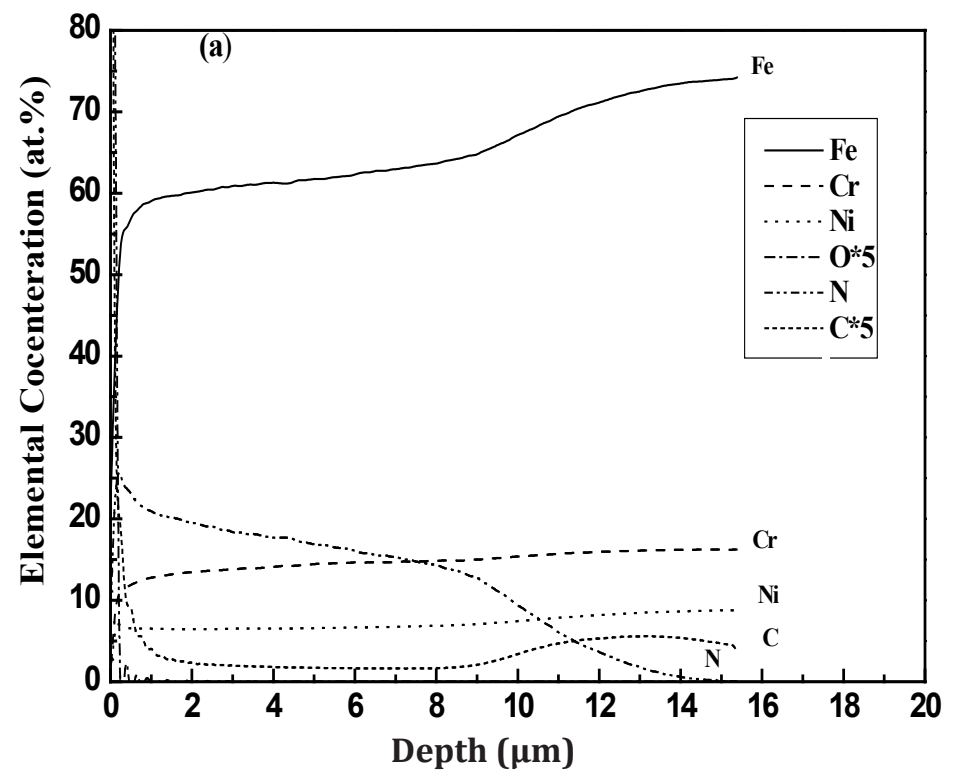

Fig1(a). The elemental concentration depth profiles of the treated sample at low cooling rate $100 \mathrm{Cm}^{3} / \mathrm{min}$ 


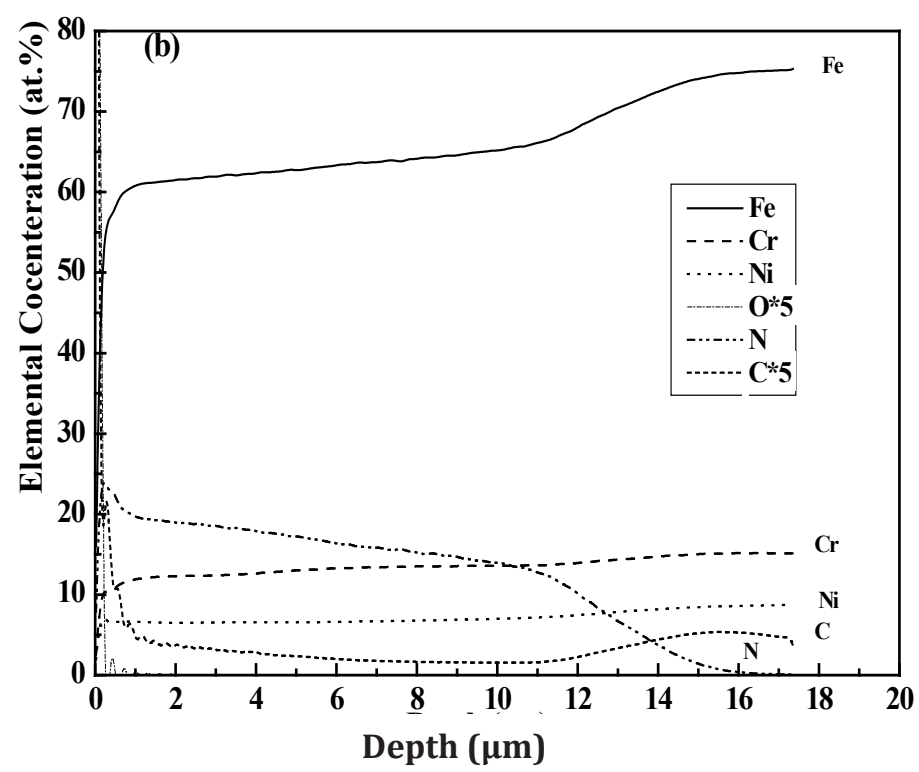

Fig1(b). The elemental concentration depth profiles of the treated sample at medium cooling rate $900 \mathrm{Cm}^{3} / \mathrm{min}^{-}$

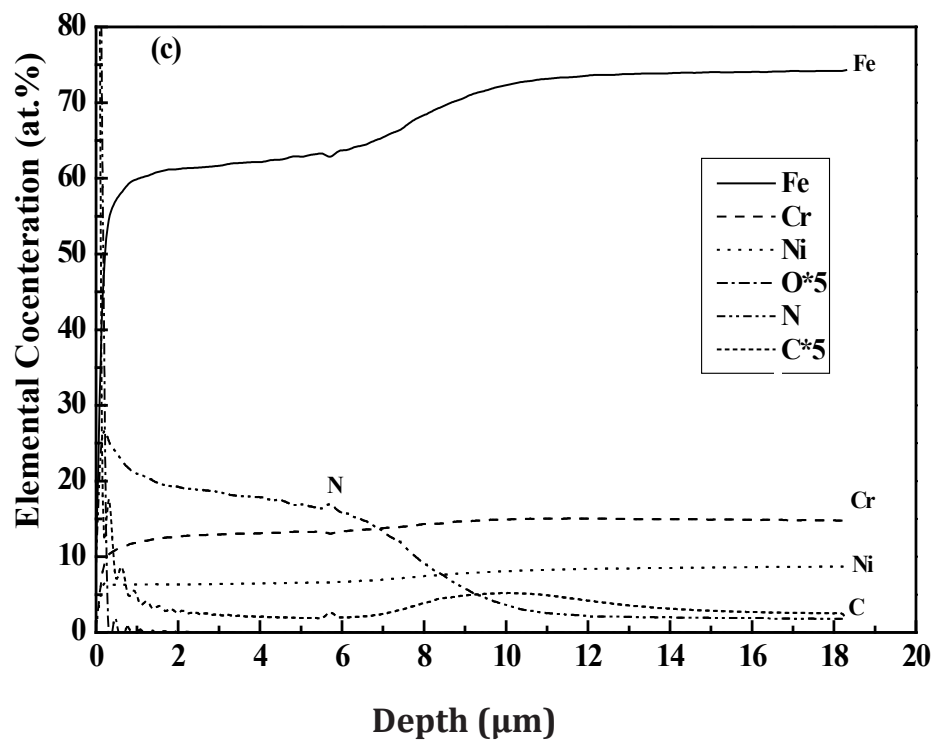

Fig1(c). The elemental concentration depth profiles of the treated sample at high cooling rate $2000 \mathrm{Cm}^{3} / \mathrm{min}$

The amount of nitrogen diffused underneath the surface is calculated by integrating the area under nitrogen depth profiles. Although the narrow variation of surface treatment temperature $\left(490-590^{\circ} \mathrm{C}\right)$, the nitrogen depth distribution has been found to be cooling rate dependent. Furthermore, the thickness of nitrogen saturation region and the total thickness of the nitrided layer have maximum values at a relatively moderate cooling rate of $900 \mathrm{Cm}^{3} / \mathrm{min}$. This might leads to that the diffusion process of reactive nitrogen species toward the bulk substrate can be partially controlled by adjusting the cooling rate.

Moreover, a small amount about 5 at $\%$ of carbon has found to be diffused underneath the surface for all treated samples due to the existence of hydrocarbon gases and carbon contamination in the reactor tube while the nitriding is processed at relatively high base pressure of $7 \times 10^{-3} \mathrm{mbar}$ [17]. 


\section{Microstructural Analysis}

The cooling rate and the plasma density can be considered as main parameters; control the microstructure of the nitrided layer. Therefore, it is more appropriate to demonstrate the microstructure of the treated samples as a function of cooling rate. Fig. 2(a-d) indicates the microstructure of the untreated austenitic substrate and the nitrided sample at different cooling rates of 100,900 and $2000 \mathrm{Cm}^{3} / \mathrm{min}$. A typical pattern of the untreated substrate is examined and shown here for comparison (Fig. 2-a). The microstructure of the nitrided layer for all treated samples shows the existence of solid solution phase of expanded austenite $\left(\gamma_{\mathrm{N}}\right)$, chemical compound phases of chromium nitrided $(\mathrm{CrN})$ and iron nitride $\left(\mathrm{Fe}_{4} \mathrm{~N}\right)$. It is observed that the supersaturation phase of $\gamma_{\mathrm{N}}$ is detected with much higher diffraction intensity than other nitride phases overall cooling rates. Furthermore, the chemical compound phases such as $\mathrm{Fe}_{4} \mathrm{~N}$ has been detected with lower intensity in the nitrided layer were created out at low surface temperature (high cooling rate) compared to that ones were created out at medium and high surface temperatures (low cooling rate). These results are in a good agreement with previous work of Williamson et al. [18], who reported that $\gamma_{\mathrm{N}}$ can be formed near $500^{\circ} \mathrm{C}$ or even $600^{\circ} \mathrm{C}$ provided that the plasma processing time at these treatment temperatures is not too long. Other research groups concluded that the formation of $\gamma_{\mathrm{N}}$ is surface temperature dependent [18-21]. However, at surface temperature of $500^{\circ} \mathrm{C}$ and below, chromium nitrides was found to be barely observed and decreased with decreasing the surface temperature [22- 23]. From figure 2 (b-d) that nitrogen expanded austenite phase achieves low lattice expansion of 1.34\%, $2 \%$, and $1.5 \%$ for samples nitrided at cooling rates of 100,900 and $2000 \mathrm{Cm}^{3} / \mathrm{min}$, respectively.

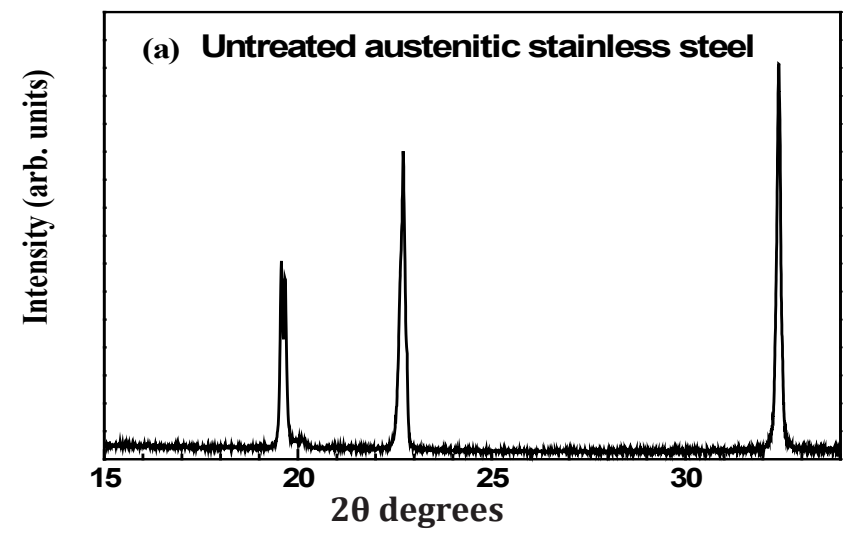

Fig2 (a). X-ray diffraction patterns of untreated sample

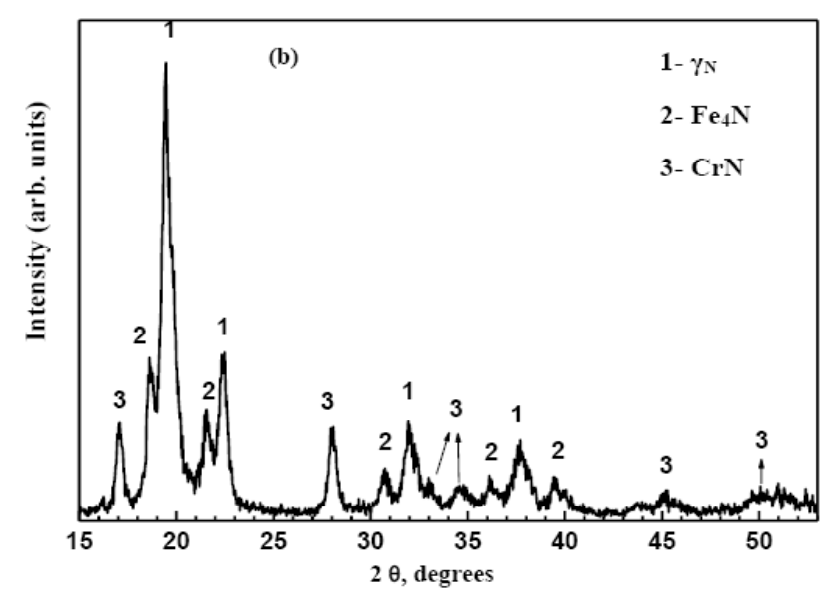

Fig2(b). X-ray diffraction patterns of treated sample nitrided at low cooling rate $100 \mathrm{Cm}^{3} / \mathrm{min}$ 


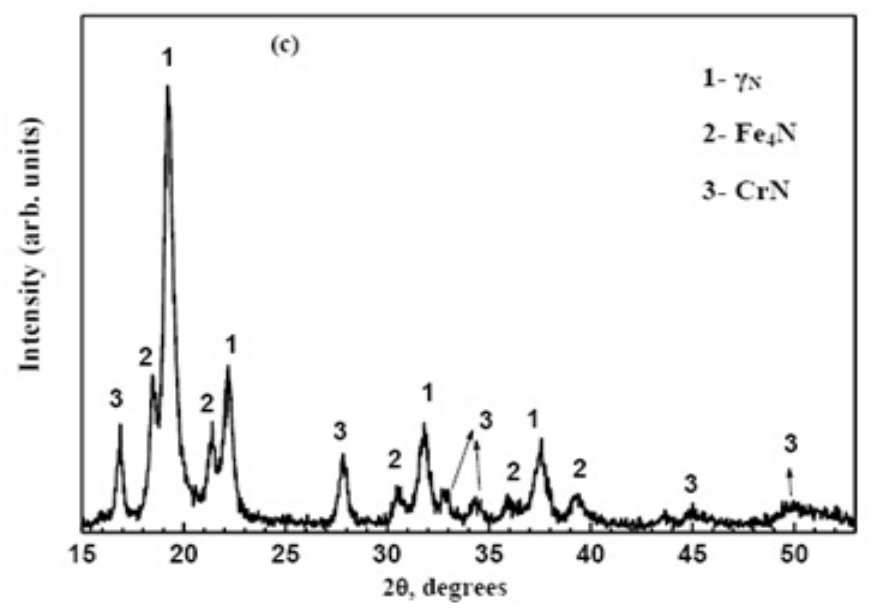

Fig2(c). X-ray diffraction patterns of treated sample nitrided at at medium cooling rate $900 \mathrm{Cm}^{3} / \mathrm{min}$

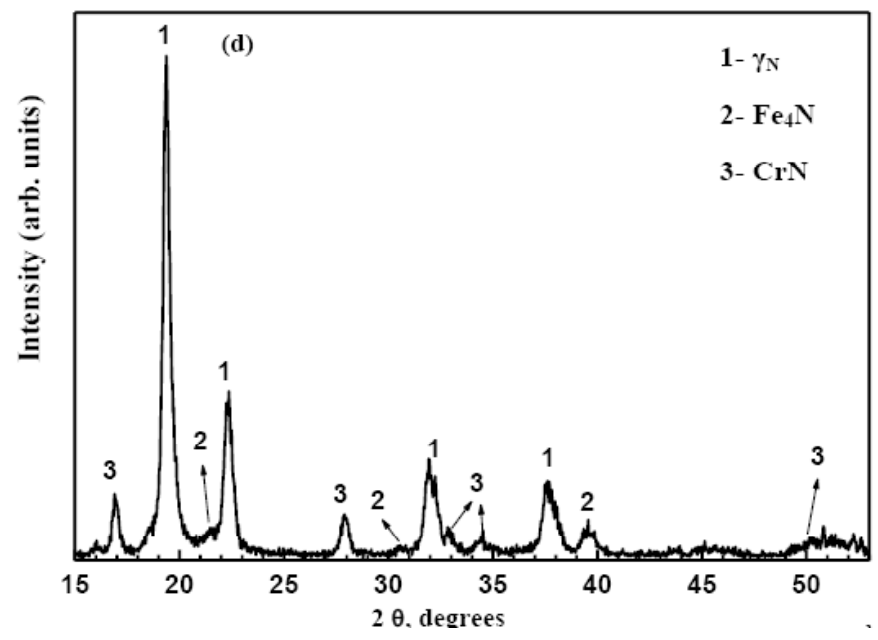

Fig2(d). X-ray diffraction patterns of treated sample nitrided at high cooling rate $2000 \mathrm{Cm}^{3} / \mathrm{min}$

\section{Surface characterization and cross-section morphology}

Fig.3 (a-d) shows the surface morphology of untreated and treated samples at different cooling rates. As one can see from Fig.3 (a) the untreated surface seems microcracks, non-uniform and randomly packed grains with thin boundaries. Furthermore, undistributed micro-porous, some dislocations and cavities have been found on the surface. At low cooling rate (Fig. 3(b)) the nitrided sample is characterized by smaller and less linked grains. Moreover, the dark precipitations of $\mathrm{CrN}$ are still observed in the microstructure. At medium cooling rate (Fig. 3(c)), heavy precipitation of chromium nitride and relatively small grains are observed for nitrided sample. At high cooling rate, as shown in Fig.3d, the nitrided surface is characterized by a relatively smaller grain size compared to that one of the untreated substrate. Moreover, few dark precipitations are observed on the grain boundaries. It was previously [24] found that the dark precipitation is related to the chemical compound phase of $\mathrm{CrN}$. Similar surface morphology has been observed for nitrided stainless steel at treatment temperature ranging from 490 to $590{ }^{\circ} \mathrm{C}$ [25]. The surface morphology we have seen is in a good agreement with the reflected pattern obtained from XRD where the intensity of $\mathrm{CrN}$ is found to be depended on the cooling rate. 

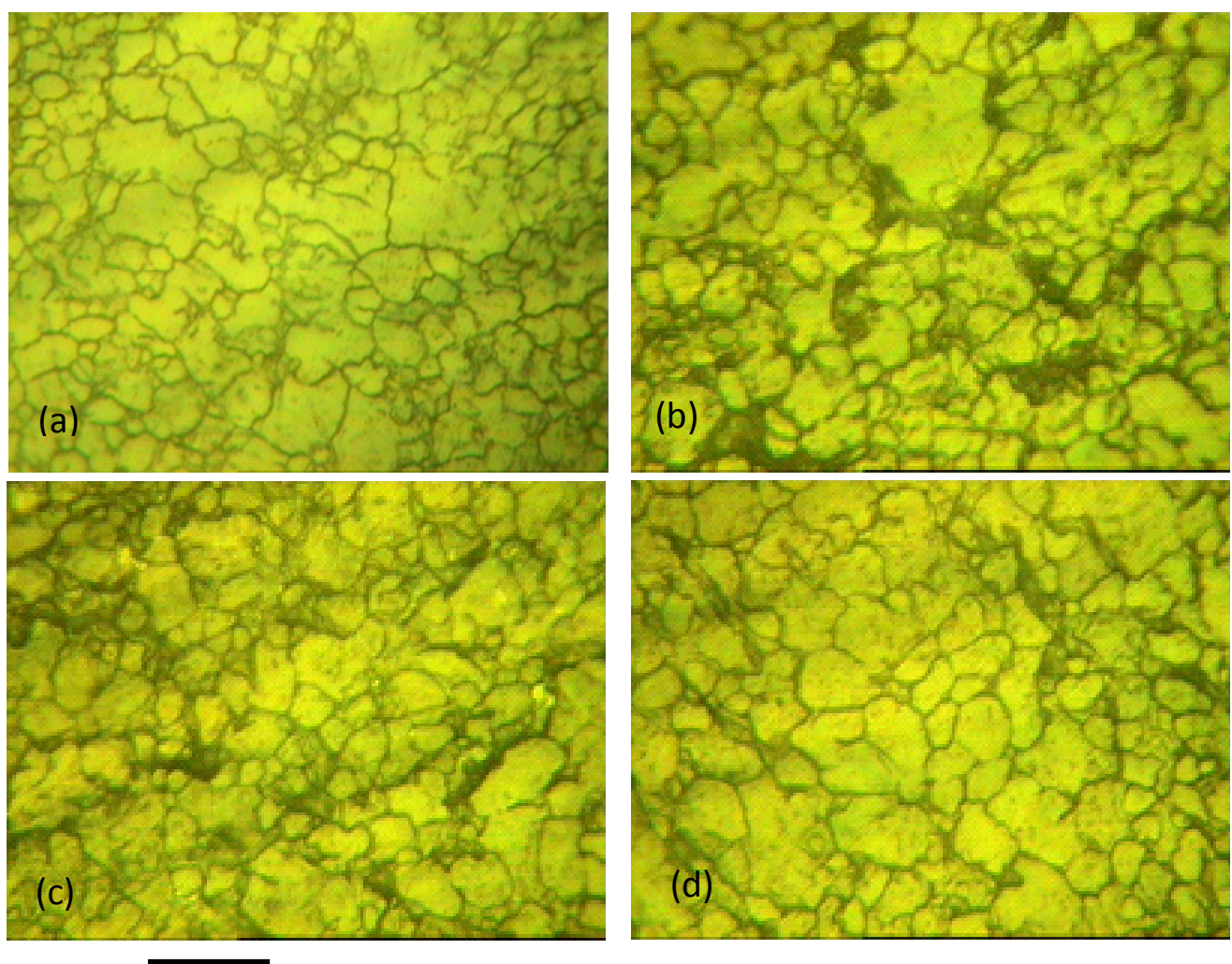

14 um

Fig3(a-d). optical microscope of a- untreated sample, b-treated sample at low cooling rate c-treated sample at medium cooling rate and $d$ - treated sample at high cooling rate

Fig. 4(a-c) shows typical cross-section microstructure of the treated samples nitrided at different cooling rates. It has been observed that the nitrided layer is characterized by a sharp interface with the bulk material for all samples. This homogeneity of nitrided (compound) layer is probably due to the domination of lattice and the high mobility of nitrogen atoms through the grains, which all enhance the formation of more uniform compound layer. Similar results have been observed for nitriding stainless steel using different plasma techniques [26]. Figure (5) shows nitrided layer thickness variation as a function of the cooling rate. It is evident that the nitrided layer thickness is cooling rates dependant and it increases continuously from 14 to $19.9 \mu \mathrm{m}$ with the increase of the cooling rate from 100 to $900 \mathrm{Cm}^{3} / \mathrm{min}$. This behaviour has been attributed to the high defect density of samples with cooling rate $\left(900 \mathrm{Cm}^{3} / \mathrm{min}\right)$. Consequently, there are a sufficient number of nucleation sites for nitrides and enough diffusion paths for nitrogen one obtains a dense compound layer. At high cooling rate ( $2000 \mathrm{Cm}^{3} / \mathrm{min}$ ), the thickness is decreased to $9.85 \mu \mathrm{m}$. This decrease can be interpreted by the penetration of nitrogen atoms is done more easily through grain boundaries. It is worthmentioning that, the first stage of this behaviour agrees well with previous published data [27].

Figure (6) shows nitriding rate variation as a function of cooling rate. The nitriding rate is accounted as a square of the nitrided layer thickness in micrometer divided by plasma processing time in second. From this figure, it can be observed that the nitriding rate increases continuously as cooling rate increases, achieving a maximum value of $0.66 \mu \mathrm{m}^{2} / \mathrm{s}$ at medium cooling rate $\left(900 \mathrm{Cm}^{3} / \mathrm{min}\right)$. The maximum value of nitriding rate $\left(0.66 \mu \mathrm{m}^{2} / \mathrm{s}\right)$ is still relatively high compared to that achieved in other publication work. Low nitriding rate of $0.027 \mu \mathrm{m}^{2} / \mathrm{s}$ 
was achieved in case of AISI 420 using low-pressure rf plasma technique [28]. A nitriding rate of $0.125 \mu \mathrm{m}^{2} / \mathrm{s}$ was recorded in case of hot work tool steel, ferritic, type 1.2343 by J.-D. Kamming et al. [29]. Also Rahman et al. [30] has used plasma nitriding for surface treatment of AISI 316 stainless steel, achieving nitriding rate of 0.02 $\mu \mathrm{m}^{2} / \mathrm{s}$ by a saddle field fast atom beam source. Liang Wang and his co-workers [31] have reported a very low nitriding rate of $0.003 \mu \mathrm{m}^{2} / \mathrm{s}$ for the same material of AISI 304 stainless steel. The huge of nitriding rate may be credited to high ion density and better chemical activation, to allow a deeper penetration of nitrogen into the samples. From the above, it can be concluded that the medium cooling rate has a positive effect on the nitriding rate. After that, it decreases significantly to $0.17 \mu \mathrm{m}^{2} / \mathrm{s}$ with the continuous increase of cooling rate to (2000 $\mathrm{Cm}^{3} / \mathrm{min}$ ). This significant decrease might be ascribed to reduction of nitrogen concentration gradient in the nitride zone.

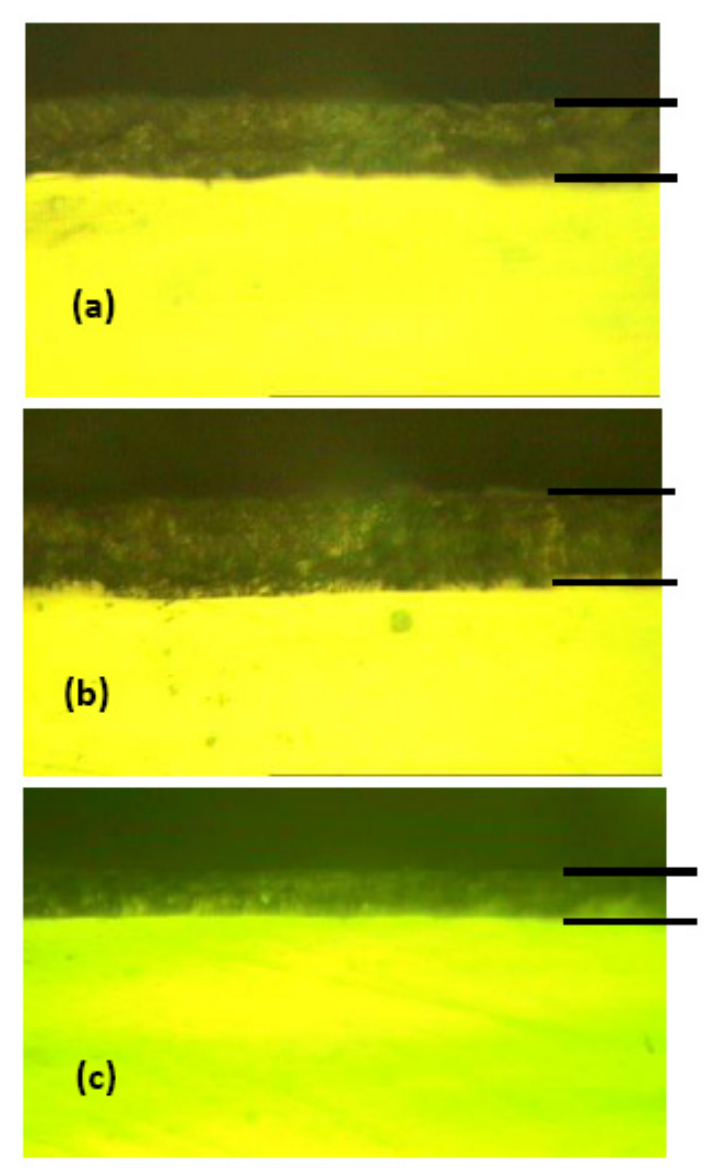

Fig4(a-c). Cross-section microstructure of the treated samples nitrided at different cooling rates, (a) at low cooling rate $100 \mathrm{Cm}^{3} / \mathrm{min}$, (b) at medium cooling rate $900 \mathrm{Cm}^{3} / \mathrm{min}$, (c) at high cooling rate $2000 \mathrm{Cm}^{3} / \mathrm{min}$ respectively

On the other side, the change of microstructure at cooling rate is a clear evidence for the increase of the surface temperature which is for sure offers different internal stress compared to that sample treated at medium cooling rate. Also, the reduction in the nitrogen mobility is previously attributed to the selective $\mathrm{N}$-Cr bonding [32]. However, nitrogen trapping effect by chromium atoms on the migration of nitrogen in 304 stainless steel might be less effective here due to that nitrogen content is high as compared to chromium concentration [33]. 


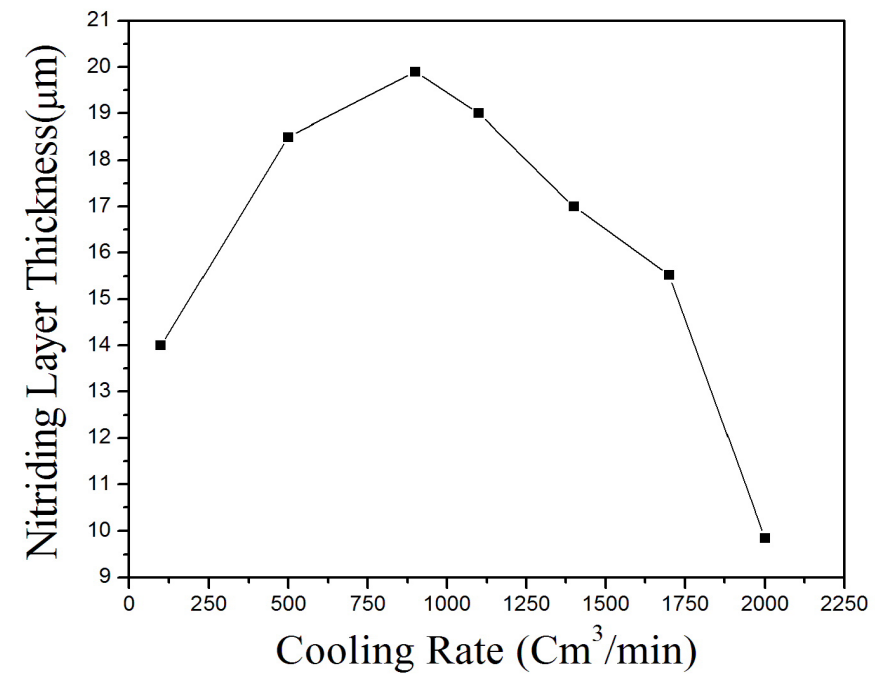

Fig(5). Nitriding Layer Thickness as function of Cooling Rate

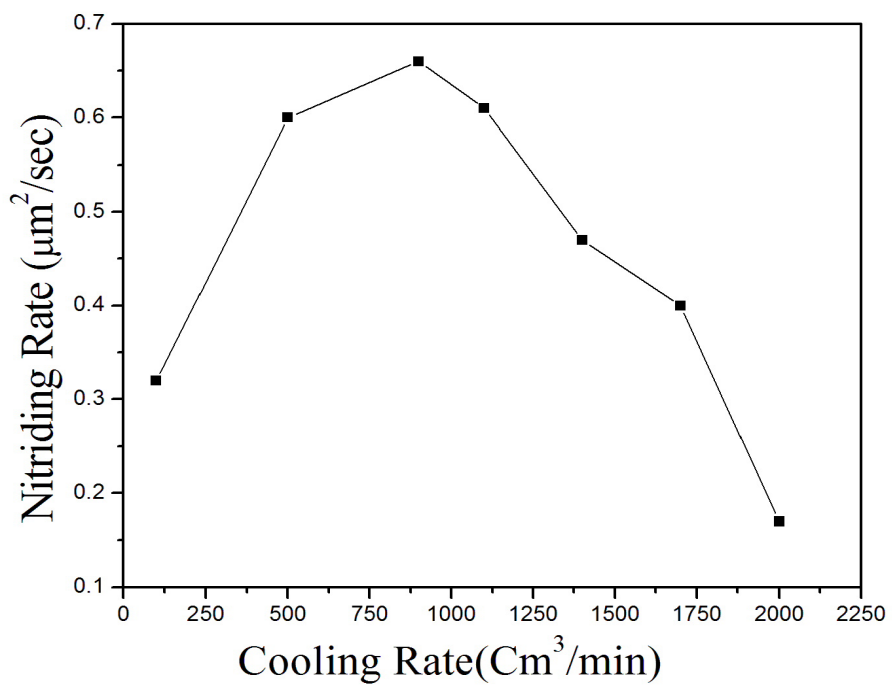

Fig(6). Nitriding Rate as function of Cooling Rate

\section{Microhardness measurements}

Figure (7) shows surface micro-hardness of nitrided samples as a function of cooling rate, measured at applied load of $100 \mathrm{~g}$. As one can see in this figure that, the surface microhardness of nitrided samples increases continuously with the increase of the cooling rate and it reaches a maximum value of $1402 \mathrm{HV} 0.1$ at medium cooling rate. However, it comes to a steep increasing with the further increase of the cooling rate. The maximum hardness value of the nitrided surface is about 7.26 times as hard as the untreated material (193HV0.1). It has been observed that the variations in the surface microhardness values match well with the variation in the microstructure and the surface morphology of the treated samples at different cooling rate. The maximum microhardness value of the nitrided layer at medium cooling rate is attributed to the microstructure which characterized by a smallest grain size, heavy precipitation of $\mathrm{CrN}$ and strongest reflection of the nitrided phases 
compared to other treated samples. Furthermore, the contribution of the bulk substrate to the measured surface hardness is expected to play a considerable role in microhardness variation [34]. It is experimentally known that thicker nitrided layer provides higher surface hardness in the presence of the soft substrate. With the high cooling rate of 1100 or more, the micro hardness value decreases. This reduction can be attributed to take off nitrogen from the interstitial sites.



Fig(7). Surface Microhardness as function of cooling Rate

\section{CONCLUSION}

In general we can conclude that the diffusion process of reactive nitrogen species toward the bulk substrate can be partially controlled by adjusting the cooling rate. The microstructure, the surface hardness and the thickness of the nitrided layer are found to be cooling rate dependant. The nitrided layer achieves good surface properties at medium cooling rate of $900 \mathrm{Cm}^{3} / \mathrm{min}$. The layer thickness and the surface microhardness have maximum values of $19.9 \mu \mathrm{m}$ and 1402 HV0.1, respectively.

\section{REFERENCES}

1. J.R. Roth, Industrial Plasma Engineering Volum 1: Principles, IOP Publishing Ltd, Bristol, 1995.

2. M. Ohring, The Material, Science of Thin Films, Academic Press, San Diego, 1992.

3. C. Alves Jr., NiteretaÇăo a Plasma: Fundamentos e AplicaÇăes, Edufrn, Natal, 2001, PP.13-86.

4. E.J.Miola, S.D. de Souza, M. Olzon-Dionysio, D. Spinelli, M.R.F. Soares, M.A.Z. Vasconcellos, C.A.dos Santos, Mater. Sci., ENG., A Struct. Mater. Prop. Microstruct. Process. 256 (1998) 60.

5. P. Schaaf, Prog. Mater. Sci. 47 (2002) 1.

6. G. Simon, M.A.Z. Vasconcellos, C.A. dos Santos, Surf. Coat. Technol. 102 (1998) 90.

7. B. Edenhofer, Heat Treat. Met. (1974) 59 part II.

8. B.-Y. Jeong, M.-H. Kim, Surf. Coat. Technol. 141 (2001) 182.

9. E. Metin, O.T. Inal, J. Mater . Sci. 22 (1987) 2783.

10. A. Sokolowska, J. Rudnicki, P. Beer, L. Maldzinski, J. Tacikowski, J. Baszkiewicz, Surf. Coat. Technol. $142-144$ (2001) 1040. 
Effect of Cooling Rate on The Plasma Nitriding Process of 304 Austenitic Stainless Steel

11. A. Alsaran, A. Celik, C. Celik, Surf. Coat. Technol. 160 (2002) 219-220.

12. L.Marot, L. Pichon, M. Drouet, A. Straboni, Mater. Lett. 44 (2000) 35-38.

13. EL-Hossary F. M., 2002, Surf. Coat. Technol., 150, 277.

14. Lepienski C.M., Nascimento F.C., Foerster C.E., da Silva S.L.R., de M. Siqueira C.J., and Alves Jr. C., 2008,Mater Sci. Eng. A, 489, 201.

15. Abd El-Rahman A. M., El-Hossary F. M., Fitz T., Negm N. Z., Prokert F., Richter E., and Möller W., 2004, Surf. Coat. Technol., 183, 268.

16. Ceschini L., and Minak G, 2008, Surf. Coat. Technol., 202, 1778.

17. Czerwiec T., He H., Weber S., Dong C., and Michel H., Surf. Coat. Technol., 200 (2006) 5289.

18. Williamson D. L., Ozturk O., Glick S., Wei R., and Wilbur P. J., Nucl. Instrum. Methods B, 59(1991) 731.

19. Xu X.L., L. Wang, Yu Z.W., and Z.K.Hei, 2000, Surf. Coat. Technol., 132, 270.

20. Wang L., Xu B., and YuShi Z., 2000, Surf. Coat. Technol., 124, 93.

21. Wei R., Vajo J. J., Matossian J. N., Wilbur P. J., Davis J. A., and Williamson D. L., 1996, Surf. Coat. Technol., 83, 235.

22. Jolanta Baranowska, and Bozena Arnold, 2006, surf .coat. technol., 200, 6623.

23. Borges C.F.M, Hennecke S., and Pfender E., 2000, Surf. Coat. Technol., 123, 112.

24. Flis J., Mankouski J., and Rolinski E., 1989, Surf. Eng. 5 (2), 151.

25. Borgioli F., Fossati A., Galvanetto E., and Bacci T., 2005, Surf.Coat.Technol. 200, 2474.

26. X, Y, Li, 2001, Surf. Eng., 17, 147.

27. B.-Y. Jeong and M.-H. Kim, 2001, Surf. Coat. Technol., 137, 249.

28. Kim S. K., Yoo J. S., Priest J. M., and Fewell M. P., 2003, Surf. Coat. Technol., 163-164, 380.

29. Kamming J.-D., Hoy R., Janssen G.C.A.M., Lugscheider E., and Maes M., 2003, Surf. Coat. Technol., 174 -175, 671.

30. Mahfujur Rahman, Julfikar Haider, and Hashmi M.S.J., 2005, Surf. Coat. Technol., 200, 1645.

31. Liang Wang, Shijun Ji, and Juncai Sun, 2006, Surf. Coat. Technol., 200, 5067.

32. Singer I.L., 1984, Vacuum, 34, 853.

33. Orhan Öztürk, and Williamson D. L, 2002, Surf. Coat. Technol., 158-159, 288.

34. Ong H. C., Chang R. P. H., Baker N., and Oliver W. C., 1997, Surf. Coat. Technol., 89, 38.

Citation: F. M. El-Hossary, N. Z. Negm, A. M. Abd El-Rahman, A. A. Abd El-Moula, S.M. Khalil. "Effect of Cooling Rate on The Plasma Nitriding Process of 304 Austenitic Stainless Steel", American Research Journal of Physics, vol 4, no. 1, 2018, pp. 1-11

Copyright (C) 2018 F. M. El-Hossary, N. Z. Negm, A. M. Abd El-Rahman, A. A. Abd El-Moula, S.M. Khalil. This is an open access article distributed under the Creative Commons Attribution License, which permits unrestricted use, distribution, and reproduction in any medium, provided the original work is properly cited. 